\title{
CrimRxiv
}

\section{Entanglement: Cybercrime Connections of an Internet Marketing Forum Population}

Masarah Paquet-Clouston, Serge-Olivier Paquette, Sebastián García, María José Erquiaga

Published on: Mar 03, 2022

DOI: $10.21428 / \mathrm{cb} 6 \mathrm{ab} 371.92880 \mathrm{e} 40$

License: Creative Commons Attribution 4.0 International License (CC-BY 4.0). 
